\title{
KAJIAN PENULISAN DIAGNOSIS DOKTER DALAM PENENTUAN KODE DIAGNOSIS LEMBAR RINGKASAN MASUK DAN KELUAR DI RUMAH SAKIT UMUM DAERAH KABUPATEN WONOGIRI
}

\author{
Sri Mariyati \\ APIKES Mitra Husada Karanganyar \\ Email: atickkrasivi@ymail.com
}

\begin{abstract}
ABSTRAK
Bahasa terminologi medis merupakan sarana komunikasi antar petugas kesehatan. Bahasa terminologi medis yang tercantum pada diagnosis seharusnya ditulis dengan terminologi medis yang tepat dan memiliki nilai informatif agar dapat membantu petugas koding mengklasifikasikan pada kondisi dalam kategori ICD yang paling spesifik. Tujuan penelitian ini adalah mengetahui ketepatan penggunaan terminologi medis dan keakuratan kode diagnosis lembar ringkasan masuk dan keluar di Rumah Sakit Umum Daerah Kabupaten Wonogiri. Hasil survei pendahuluan yang dilakukan terhadap 10 dokumen rawat inap bulan Maret tahun 2012 di RSUD dr. Soediran Mangun Sumarso Kab. Wonogiri menunjukkan bahwa penggunaan bahasa terminologi yang tidak tepat $40 \%$ dengan ketidaktepatan kode diagnosis akhir $50 \%$.

Jenis Penelitian ini adalah deskriptif dengan pendekatan retrospektif. Populasi dalam penelitian ini adalah seluruh dokumen rekam medis rawat inap di RSUD dr. Soediran Mangun Sumarso Kabupaten Wonogiri. Besar populasi adalah 1248 lembar ringkasan masuk dan keluar pada bulan Maret tahun 2012. Teknik pengambilan sampling dengan sampling sistematis. Besar sampel yang digunakan 125 lembar ringkasan masuk dan keluar. Analisis data menggunakan analisis deskriptif. Ketepatan penggunaan bahasa terminologi medis sebesar 82 lembar ringkaran masuk dan keluar $(65,6 \%)$ dan ketidaktepatan penggunaan bahasa terminologi medis sebesar 43 lembar ringkaran masuk dan keluar (34,4\%). Keakuratan kode diagnosis sebesar 101 lembar ringkaran masuk dan keluar $(80,8 \%)$ dan ketidakakuratan kode diagnosis sebesar 24 lembar ringkaran masuk dan keluar $(19,2 \%)$.

Ketepatan penggunaan bahasa terminologi medis sebesar 82 lembar ringkasan masuk dan keluar $(65,6 \%)$ sedangkan ketidaktepatan penggunaan bahasa terminologi medis sebesar 43 lembar ringkasan masuk dan keluar $(34,4 \%)$. Disarankan menggunakan bahasa terminologi medis yang tepat untuk menunjang keakuratan kode diagnosis berdasarkan ICD-10.
\end{abstract}

\section{Kata kunci : Terminologi medis dan keakuratan kode}




\section{PENDAHULUAN}

Diagnosis adalah identifikasi terhadap penyakit yang diderita oleh pasien. Dalam formulir ringkasan masuk dan keluar (RM 1) terdapat beberapa diagnosis diantaranya diagnosis masuk, diagnosis akhir, diagnosis lain dan diagnosis komplikasi. Diagnosis akhir merupakan diagnosis yang ditangani atau diperiksa selama episode perawatan yang relevan. Diagnosis ini seharusnya ditulis dengan terminologi medis yang tepat dan memiliki nilai informatif agar dapat membantu petugas koding mengklasifikasikan pada kondisi dalam kategori ICD yang paling spesifik. Menurut Nuryati (2010) terminologi medis adalah sarana komunikasi antara mereka yang berkecimpung langsung atau tidak langsung dibidang pelayanankesehatan.

Berdasarkan Surat Keputusan Menteri Kesehatan Nomor. 377/Menkes/SK/III/2007 tentang Standar Profesi Perekam Medis dan Informasi Kesehatan dijelaskan bahwa salah satu kompetensi perekam medis adalah klasifikasi dan kodefikasi penyakit, masalahmasalah yang berkaitan dengan kesehatan dan tindakan medis. Penentuan kode diagnosis yang tepat juga dipengaruhi oleh peran petugas koding dalam menentukan lead term yang tepat untuk menentukan kode penyakit dan tindakan dengan tepat sesuai klasifikasi yang diberlakukan di Indonesia (ICD-10) (Kepmenkes RI, 2007).

Hasil survei pendahuluan yang dilakukan terhadap 10 dokumen rawat inap bulan Maret tahun 2012 di RSUD dr. Soediran Mangun Sumarso Kab. Wonogiri menunjukkan bahwa penggunaan bahasa terminologi yang tidak tepat $70 \%$ dengan ketidaktepatan kode diagnosis akhir $30 \%$. Salah satu diagnosis yang tertulis pada lembar ringkasan masuk dan keluar adalah BBLR dengan kode Z38.0. Hal tersebut belum tepat karena Z38.0 untuk singleton born in hospital. Terminologi medis yang tepat seharusnya Low birth weight atau $L B W$ dengan kode O44.1 Hal ini menunjukkan penggunaan terminologi medis merupakan salah satu factor penyebab ketidakakuratan kode diagnosis. Petugas koding yang kurang teliti dalam memilih lead term berdasarkan penulisan diagnosis akan mengakibatkan kode tidak akurat. Berdasarkan data tersebut maka perlu dilakukan penelitian yang membahas tentang ketepatan penggunaan terminologi medis dan keakuratan kode diagnosis pada lembar ringkasan masuk dan keluar di Rumah Sakit Umum Daerah Kabupaten Wonogiri.

\section{Kajian Pustaka}

\section{Terminologi Medis}

Menurut Nuryati (2011) bahwa terminologi medis adalah ilmu peristilahan medis yang merupakan sarana komunikasi antara mereka yang berkecimpung langsung/tidak langsung dibidang pelayanan medis. Menurut Hatta (2010), istilah-istilah penyakit atau kondisi gangguan kesehatan yang didaftar dalam nomenklatur harus sesuai dengan istilah yang digunakan didalam suatu sistem klasifikasi penyakit.

\section{Unsur terminologi medis}


Sebagian besar struktur istilah medis tersusun dari 3 (tiga) unsur kata, yakni prefix, root, dan suffix. Dalam struktur setiap kata/istilah harus memiliki minimal satu root. Tidak semua istilah medis terdiri dari tiga unsur prefix, root dan suffix, adakalanya satu istilah terdiri hanya dua unsur kata, mungkin hanya terdiri dari prefix dan root atau root dan suffix saja. Namun tidak jarang juga istilah memiliki lebih dari tiga unsur kata.

\section{Diagnosis}

$\begin{array}{ccc}\text { Kondisi utama } & \text { adalah } & \text { suatu } \\ \text { diagnosis/kondisi } & \text { kesehatan } & \text { yang }\end{array}$ menyebabkan pasien memperoleh perawatan/pemeriksaan, yang ditegakkan pada akhir episode pelayanan dan bertanggungjawab atas kebutuhan sumber daya pengobatannya.

\section{Sistem Klasifikasi Penyakit}

Nomenklatur atau terminologi medis merupakan sistem yang digunakan untuk menata daftar kumpulan istilah medis, penyakit, gejala dan prosedur. Penggunaan lebih dari satu perolehan istilah untuk penyakit yang sama menyulitkan dalam pengumpulan dan perolehan informasi morbiditas dan mortalitas yang akurat dan tepat. Untuk menstandarkan bahasa medis maka dikembangkan nomenklatur penyakit, sistem klasifikasi penyakit dan perbendaharaan istilah medis klinis. Sistem klasifikasi penyakit adalah sistem yang mengelompokkan penyakit-penyakit dan prosedur-prosedur sejenis kedalam satu grup nomor kode penyakit dan tindakan yang sejenis.
Petunjuk Untuk Pencatatan Informasi Diagnostik Bagi Analisa Kondisi Tuggal

\section{Data Morbiditas}

Dokter yang merawat bertanggungjawab atas pengobatan pasien harus memilih kondisi utama untuk dicatat, sama halnya dengan kondisi lain pada episode perawatan. Informasi ini dikelola secara sistematis dengan menggunakan metode-metode pencatatan yang baku. Catatan yang lengkap dan baik penting untuk penanganan pasien yang baik dan merupakan sumber data epidemiologi dan statistik lain yang bernilai, dan statistik lain yang bernilai, data statistik morbiditas dan masalah-masalah lain dalam perawatan kesehatan.

Setiap pernyataan diagnosis harus mempunyai nilai informatif untuk dapat diklasifikasi pada kondisi dalam kategori ICD yang paling spesifik.

\section{METODE}

Jenis penelitian yang akan dilakukan adalah penelitian deskriptif. Penelitian deskriptif yaitu penelitian yang menggambarkan ketepatan penggunaan terminologi medis dan keakuratan kode diagnosis pada lembar ringkasan masuk dan keluar. Pendekatan yang digunakan adalah pendekatan retrospektif yaitu data penelitian yang digunakan adalah data masa lampau (sebelumnya) (Arief M, 2009).

Populasi dalam penelitian adalah seluruh dokumen rekam medis rawat inap di RSUD dr. Soediran Mangun Sumarso kabupaten Wonogiri tahun 2012. Besar populasi pada bulan maret tahun 2012 sejumlah 1248 dokumen rekam medis. Teknik pengambilan 
sample (sampling) menggunakan sampling sistematis. Jumlah sampel yang diteliti adalah $10 \%$ dari populasi yaitu 125 dokumenrekam medis. Analisis data menggunakan analisis deskriptif untuk mengkaji penulisan diagnosis dokter dalam penentuan kode diagnosis.

\section{HASIL}

Tabel 1. Rekapitulasi

KetepatanPenggunaan Terminologi

Medis Pada Lembar Ringkasan Masuk

Dan Keluar

\begin{tabular}{lcc}
\hline Ketepatan & \multicolumn{2}{c}{ Jumlah } \\
\cline { 2 - 3 } $\begin{array}{c}\text { penggunaan } \\
\text { terminologi } \\
\text { medis }\end{array}$ & $\mathrm{n}$ & $\%$ \\
\hline Tepat & 82 & 65,6 \\
Tidak Tepat & 43 & 34,4 \\
Jumlah & 125 & 100 \\
\hline
\end{tabular}

Tabel 1 menunjukkan rekapitulasi penggunaan terminologi medis yang tepat sebesar 82 lembar ringkasan masuk dan keluar $(65,6 \%)$. Penggunaan terminologi medis yang tidak tepat sebesar 43 lembar ringkasan masuk dan keluar $(34,4 \%)$.

Tabel 2. Penggunaan Terminologi Medis Yang Tepat Pada Lembar Ringkasan Masuk Dan Keluar

\begin{tabular}{|c|c|c|}
\hline No & Diagnosis RM1 & $\begin{array}{l}\text { Terminologi } \\
\text { Medis }\end{array}$ \\
\hline 1 & Neonatus aterm & Neonatus \\
\hline 2 & $P P H$ & $\begin{array}{l}\text { Postpartum } \\
\text { hemorrhage }\end{array}$ \\
\hline 3 & $\begin{array}{l}\text { Riw.APH e/c } \\
\text { susp. PPt pada } \\
\text { sekundigravida } \\
\text { h.preterm bdp sc } \\
7 \text { th yll }\end{array}$ & $\begin{array}{l}\text { Placenta Previa } \\
\text { total with } \\
\text { hemorrhage }\end{array}$ \\
\hline 4 & $\begin{array}{l}\text { Abortus } \\
\text { imminent }\end{array}$ & $\begin{array}{l}\text { Abortus } \\
\text { imminent }\end{array}$ \\
\hline
\end{tabular}

Data selengkapnya terlampir

Tabel 2 menunjukkan penggunaan terminologi medis yang tepat. Hal ini dapat dilihat pada kasus nomor 2 yaitu pada diagnosis $P P H$ yang merupakan singkatan dari postpartum hemorrhage. Pada kasus nomor 4 yaitu pada diagnosis abortus imminent.

Tabel 3. Penggunaan Terminologi Medis Yang Tidak Tepat

\begin{tabular}{lll}
\hline No & $\begin{array}{l}\text { Diagnosis RM } \\
1\end{array}$ & \multicolumn{1}{c}{$\begin{array}{c}\text { Terminologi } \\
\text { medis }\end{array}$} \\
\hline 1 & $\begin{array}{l}\text { Demam } \\
\text { berdarah }\end{array}$ & $\begin{array}{l}\text { DHF (dengue } \\
\text { hemorrhagic } \\
\text { fever) }\end{array}$ \\
2 & $\begin{array}{l}\text { Kala II tak } \\
\text { maju e/c kejan } \\
\text { ibu tidak } \\
\text { adekuat }\end{array}$ & $\begin{array}{l}\text { Prolonged second } \\
\text { stage }\end{array}$ \\
3 & Bekas TB & $\begin{array}{l}\text { Sequelae TB } \\
\text { (tuberculosis) }\end{array}$ \\
\hline Data selengkapnya terlampir
\end{tabular}

Tabel 3 menunjukkan penggunaan terminologi medis yang tidak tepat. Hal ini dapat dilihat pada kasus nomor 1 yaitu pada diagnosis demam berdarah. Pada kasus nomor 2 yaitu pada diagnosis kala ii tak maju e/c kejan ibu tidak adekuat.

Tabel 4. Rekapitulasi Keakuratan Kode Diagnosis Berdasarkan Terminologi Medis Pada Lembar Ringkasan Masuk Dan Keluar

\begin{tabular}{lccc}
\hline Keakuratan & kode & \multicolumn{2}{c}{ Jumlah } \\
\cline { 3 - 4 } diagnosis $\quad$ pada & $\mathrm{n}$ & $\%$ \\
& & \\
lembar RM 1 & & \\
\hline Akurat & 101 & 80,8 \\
Tidak akurat & 24 & 19,2 \\
Jumlah & 125 & 100 \\
\hline
\end{tabular}

Tabel 4 menunjukkan rekapitulasi keakuratan kode diagnosis berdasarkan 
terminologi medis pada lembar ringkasan masuk dan keluar. Kode diagnosis yang akurat sebesar 101 lembar ringkasan masuk dan keluar (80,8 \%). Kode diagnosis yang tidak akurat sebesar 24 lembar ringkasan masuk dan keluar $(19,2 \%)$.

Tabel 5. Kode Diagnosis Yang Akurat Pada Lembar Ringkasan Masuk Dan Keluar

\begin{tabular}{|c|c|c|c|c|}
\hline No & $\begin{array}{c}\text { Diagnosi } \\
\text { s pada } \\
\text { lembar } \\
\text { rm } 1\end{array}$ & $\begin{array}{c}\text { Termino } \\
\text { logi } \\
\text { medis }\end{array}$ & $\begin{array}{l}\text { Lead } \\
\text { term }\end{array}$ & Kode \\
\hline 1 & $\begin{array}{l}\text { Neonatu } \\
\text { s aterm }\end{array}$ & $\begin{array}{l}\text { Neonatu } \\
s\end{array}$ & Neonatus & Z38.0 \\
\hline 2 & $\begin{array}{l}\text { Typhoid } \\
\text { fever }\end{array}$ & $\begin{array}{l}\text { Typhoid } \\
\text { fever }\end{array}$ & Typhoid & A01.0 \\
\hline 3 & $\begin{array}{l}D B D \\
\text { grade III }\end{array}$ & $\begin{array}{l}\text { DHF } \\
\text { (dengue } \\
\text { hemorrh } \\
\text { agic } \\
\text { fever) }\end{array}$ & Dengue & A91 \\
\hline
\end{tabular}

Data selengkapnya terlampir

Tabel 5 menunjukkan kode diagnosis pada lembar ringkasan masuk dan keluar yang akurat. Hal ini dapat dilihat pada kasus nomor 1 yaitu pada diagnosis neonatus aterm dengan kode diagnosis Z38.0. Pada kasus nomor 2 yaitu pada diagnosis $D B D$ grade III dengan kode diagnosis A91.

Tabel 6. Kode diagnosis yang tidak akurat pada lembar ringkasan masuk dan keluar

\begin{tabular}{ccccc}
\hline No & Diagnosis & Terminol & Lead & Kode \\
& pada & ogi & term & RS \\
& lembar rm & medis & & \\
1 & & & \\
\hline
\end{tabular}

\begin{tabular}{|c|c|c|c|c|}
\hline 1 & $\begin{array}{l}\text { Riw.APH } \\
\text { e/c susp. } \\
\text { PPt pada } \\
\text { sekundigra } \\
\text { vida } \\
\text { h.preterm } \\
\text { bdp sc } 7 \text { th } \\
\text { yll }\end{array}$ & $\begin{array}{c}\text { Placenta } \\
\text { Previa } \\
\text { total with } \\
\text { hemorrhag } \\
e\end{array}$ & $\begin{array}{c}\text { hemorr } \\
\text { hage }\end{array}$ & O46.9 \\
\hline 2 & $\begin{array}{l}\text { Decomp } \\
\text { cordis } \\
\text { IHD }\end{array}$ & $\begin{array}{l}\text { Decompe } \\
\text { nsatio } \\
\text { cordis in } \\
\text { ischemic } \\
\text { heart } \\
\text { diseases }\end{array}$ & $\begin{array}{l}\text { decom } \\
\text { pensati } \\
\text { on }\end{array}$ & O42.0 \\
\hline 3 & $\begin{array}{l}\text { Neo BBLR } \\
\text { cb smk }\end{array}$ & $\begin{array}{l}\text { Low birth } \\
\text { weigt }\end{array}$ & infant & Z38.0 \\
\hline
\end{tabular}

Tabel 6 menunjukkan kode diagnosis yang tidak akurat. Hal ini dapat dilihat pada kasus nomor 1 yaitu pada diagnosis riw.APH e/c susp. PPt pada sekundigravida h.preterm bdp sc 7 th yll dengan kode diagnosis O46.9. Pada kasus nomor 3 yaitu pada diagnosis neo BBLR cb smk dengan kode diagnosis Z38.0.

\section{PEMBAHASAN}

Ketepatan penggunaan bahasa terminologi medis pada diagnosis lembar ringkasan masuk dan keluar tahun 2012 di Rumah Sakit Umum Daerah

\section{Kabupaten Wonogiri}

Terminologi medis adalah ilmu tentang bahasa medis yang digunakan sebagai sarana komunikasi bagi orang-orang yang berperan langsung atau tidak langsung dibidang pelayanan kesehatan. Terminologi medis ini harus sesuai dengan istilah yang digunakan dalam suatu sistem klasifikasi penyakit untuk menunjang keakuratan kode penyakit (Hatta, 2010). Ketepatan bahasa terminologi medis pada lembar RM 1 tahun 2012 sebesar 
82 dokumen dari 125 dokumen rekam medis. Hal ini dapat dilihat pada tabel 2 kasus nomor 1 diagnosis neonatus aterm. Neonatus aterm merupakan bahasa terminologi medis yang berasal dari bahasa latin.Neonatus aterm memiliki unsur-unsur bahasa yaitu neo- (prefix), nat- (root), -us (suffix), a- (prefix), dan -term (root). Kasus nomor 3 diagnosis riw.APH e/c susp. PPt pada sekundigravida h.preterm bdp sc 7 th yll merupakan bahasa terminologi medis. APH merupakan singkatan dari antepartum hemorrhage dan PPt adalah singkatan dari placenta previa total. Riw.APH e/c susp. PPt pada sekundigravida h.preterm bdp sc 7 th $y l l$ memiliki unsur-unsur pembentuk yaitu ante (prefix), partum (root), hemo (root), rhage (suffix), placenta (root), previa (root) dantotalis (root). Penggunaan bahasa terminologi yang tepat memiliki minimal satu root dan menggunakan bahasa terminologi medis yang sesuai dengan sistem klasifikasi penyakit. Tetapi perlu diperhatikan bahwa tidak semua bahasa terminologi medis dapat di bagi menjadi unsusr-unsur pembentuk. Bahasa terminologi medis yang dapat dibagi menjadi unsur-unsur pembentuk adalah bahasa greek dan bahasa latin.

Penggunaan lebih dari satu perolehan istilah untuk penyakit yang sama menyulitkan dalam pengumpulan dan perolehan informasi morbiditas dan mortalitas yang akurat dan tepat (Hatta, 2010). Penggunaan bahasa terminologi medis yang tidak tepat sebesar 43 dokumen rekam medis dari 125 dokumen rekam medis. Penggunaan bahasa terminologi medisyang tidak tepat terdapat pada tabel 3 kasus nomor 1 diagnosis demam berdarah. Demam berdarah bukan merupakan bahasa terminologi medis sehingga tidak memiliki unsur-unsur pembentuk terminologi medis. Bahasa terminologi medis yang tepat adalah dengue hemorrhagic fever (DHF). Dengue hemorrhagic fevermemiliki unsur-unsur pembentuk dengue (root), hemo- (root),rhagic (suffix) dan fever (berasal dari bahasa inggris). Pada tabel 3 kasus nomor 3 diagnosis bekas TB bukan merupakan bahasa terminologi medis sehingga tidak memiliki unsur pembentuk terminologi medis. Terminologi medis yang tepat adalah sequelae tuberculosis atau dapat disingkat sequelae $T B$ yang memiliki unsur-unsur pembentuk yaitu tubercul- (root) dan -osis (suffix). Berdasarkan hasil pengamatan penggunaan bahasa terminologi medis yang tidak tepat disebabkan oleh penulisan diagnosis yang menggunakan bahasa Indonesia, kurangnya sosialisasi tentang penggunaan bahasa terminologi medis yang tepat sehingga petugas medis belum mengetahui secara luas dampak yang ditimbulkan dari ketidaktepatan penggunaan bahasa terminologi medis.

\section{Keakuratan kode diagnosis lembar ringkasan masuk dan keluar tahun 2012 di RSUD dr. Soediran Mangun Soemarso Kab. Wonogiri}

Pengkodean morbiditas sangat bergantung pada diagnosis yang ditetapkan dokter yang merawat pasien untuk dijadikan dasar pengukuran statistik morbiditas 
(Hatta, 2010). Terminologi medis yang tercantum pada diagnosis digunakan sebagai dasar penentuan kode. Kualitas data terkode memiliki peran penting dalam meningkatkan keakuratan kode yang dihasilkan. Ketepatan bahasa terminologi medis pada lembar RM 1 bulan Maret tahun 2012 sebesar 82 dokumen dari 125 dokumen rekam medis.Penggunaan bahasa terminologi medis yang tepat dengan kode diagnosis yang akurat sebesar 66 dokumen rekam medis. Hal ini dapat dilihat pada tabel 4.5 kasus nomor 1 diagnosis neonatus atermkode Z38.0. Kode Z38.0 adalah kode untuk singleton born in hospital merupakan kode yang akurat untuk diagnosis tersebut. Penggunaan bahasa terminologi medis yang tepat dengan kode diagnosis yang tidak akurat sebesar 16 dokumen rekam medis. Hal ini dapat dilihat pada tabel 4.6 kasus nomor 2 diagnosis decomp cordis IHD kode I51.9. kode I51.9 bukan merupakan kode yang akurat untuk diagnosis decomp cordis IHD karena I51.9 adalah heart diseases, unspecified. Kode ini tidak akurat, sehingga kode yang akurat adalah I25.9 yaitu chronic ischemic heart diseases, unspecified. Hal ini dapat terjadi karena teknik penelusuran yang tidak memperhatikan setiap petunjuk catatan yang muncul dibawah istilah pada ICD-10 volume 3(Hatta, 2010). Sehingga walaupun terminologi medis yang digunakan sudah tepat tidak menjamin kode yang dihasilkan adalah kode yang akurat. Petugas koding juga harus memperhatikan setiap komponen dalam diagnosis untuk dicari dalam ICD-10.
Penggunaan bahasa terminologi medis yang tidak tepat sebesar 43 dokumen rekam medis dari 125 dokumen rekam medis. Penggunaan bahasa terminologi medis yang tidak tepat dengan kode diagnosis yang tidak akurat sebesar 8 dokumen rekam medis. Hal ini dapat dilihat pada tabel 4.6 kasus nomor 3 diagnosis Neo BBLR cb smk kode Z38.0. $B B L R$ bukan merupakan bahasa terminologi medis. Terminologi medis yang tepat untuk BBLR adalah LBW (Low Birth Weight). Kode Z38.0 bukan merupakan kode yang akurat karena Z38.0 adalah singleton, born in hospital. Kode yang akurat adalah P07.1 yaitu other low birth weight. Hal ini dapat terjadi karena kesalahan petugas koding dalam memilih lead term sehingga penentuan kode menjadi tidak akurat.Lead term sebaiknya berupa penyakit atau cedera yang merupakan kata benda yang memaparkan kondisi patologis (Hatta, 2010)

Penggunaan bahasa terminologi medis yang tidak tepat dengan kode akurat sebesar 35 dokumen rekam medis. Hal ini dapat dilihat pada tabel 4.5 kasus nomor 3 diagnosis $D B D$ grade III kode A91. DBD grade III bukan merupakan bahasa terminologi medis. Diagnosis ini dapat ditulis dengan DHF grade III. Hal ini menunjukkan, meskipun penggunaan bahasa terminologi medis yang tidak tepat tetapi petugas sudah terbiasa dengan bahasa tersebut maka akan mudah bagi petugas untuk melakukan kodefikasi.

\section{SIMPULAN}

Ketepatan bahasa terminologi medis pada dokumen rekam medis rawatinap bulan 
Maret tahun 2012 sebesar 82 dokumen rekam medis. Ketidaktepatan penggunaan bahasa terminologi medis pada dokumen rekam medis rawat inap bulan Maret tahun 2012 sebesar 43 dokumen rekam medis. Keakuratan kode diagnosis berdasarkan terminologi medis pada dokumen rekam medis bulan Maret tahun 2012 sebesar 101 dokumen rekam medis. Sedangkan ketidakakuratan kode diagnosis sebesar 24 dokumen rekam medis.

\section{DAFTAR PUSTAKA}

Departemen Kesehatan RI., Badan PPSDM., 2007, Standar Profesi Perekam Medis dan Informasi Kesehatan, Jakarta

Hatta, Gemala R, editor. 2010. Pedoman Manjemen Informasi Kesehatan di Sarana Pelayanan Kesehatan. Jakarta:UI-Press

WHO. 2005. International Statistical Classification of Disease and Related Health Problem Tenth Revision. Volume 1.

_ 2005. International Statistical Classification of Disease and Related Health Problem Tenth Revision. Volume 2.

2005. International Statistical Classification of Disease and Related Health Problem Tenth Revision. Volume3 